\title{
Clinical Decision Support System for Diabetes Based on Ontology Reasoning and TOPSIS Analysis
}

\author{
Rung-Ching Chen, ${ }^{1}$ Hui Qin Jiang, ${ }^{1,2}$ Chung-Yi Huang, ${ }^{1,3}$ and Cho-Tsan Bau ${ }^{4}$ \\ ${ }^{1}$ Department of Information Management, Chaoyang University of Technology, Taichung, Taiwan \\ ${ }^{2}$ College of Computer and Information Engineering, Xiamen University of Technology, No. 600, Ligong Rd., Jimei District, Xiamen, \\ Fujian, China \\ ${ }^{3}$ Library, Chienkuo Technology University, Changhua, Taiwan \\ ${ }^{4}$ Taichung Hospital, Ministry of Health and Welfare, Executive Yuan, Taichung, Taiwan
}

Correspondence should be addressed to Rung-Ching Chen; crching@cyut.edu.tw

Received 2 July 2017; Accepted 10 September 2017; Published 26 October 2017

Academic Editor: Weide Chang

Copyright (C) 2017 Rung-Ching Chen et al. This is an open access article distributed under the Creative Commons Attribution License, which permits unrestricted use, distribution, and reproduction in any medium, provided the original work is properly cited.

\begin{abstract}
Introduction. Although a number of researchers have considered the positive potential of Clinical Decision Support System (CDSS), they did not consider that patients' attitude which leads to active treatment strategies or HbAlc targets. Materials and Methods. We adopted the American Diabetes Association (ADA) and the European Association for the Study of Diabetes (EASD) published to propose an $\mathrm{HbAlc}$ target and antidiabetic medication recommendation system for patients. Based on the antidiabetic medication profiles, which were presented by the American Association of Clinical Endocrinologists (AACE) and American College of Endocrinology (ACE), we use TOPSIS to calculate the ranking of antidiabetic medications. Results. The endocrinologist set up ten virtual patients' medical data to evaluate a decision support system. The system indicates that the CDSS performs well and is useful to $87 \%$, and the recommendation system is suitable for outpatients. The evaluation results of the antidiabetic medications show that the system has $85 \%$ satisfaction degree which can assist clinicians to manage T2DM while selecting antidiabetic medications. Conclusions. In addition to aiding doctors' clinical diagnosis, the system not only can serve as a guide for specialty physicians but also can help nonspecialty doctors and young doctors with their drug prescriptions.
\end{abstract}

\section{Introduction}

The Institute of Medicine [1] defines patient-centered care strategy as "providing care that is respectful of and responsive to individual patient preferences, needs, and values and ensuring that patient values guide all clinical decisions." Clinical practitioners need to select different drugs to meet the needs of patients. However, patients with type 2 diabetes mellitus exhibit tremendous differences in phenotypes resulting in significant heterogeneity in clinical results. Consequently, clinical practitioners cannot be certain whether a prescription for a particular patient is the best.
Clinical decision support system (CDSS) may help clinicians, patients, and others to suggest patient-appropriate evidence-based treatment options. Ontologies are essential tools for the organization and representation of knowledge [2-7]. Ontologies contain the collection of patients, symptoms, diseases, diagnoses, treatments, and drug information, thereby creating a healing strategy according to patient's requirements to reconfigure a clinical decision support system [8]. Some of the studies suggested using ontologies to build clinical guidelines and care plans [5, 9-12].

In most of the knowledge ontologies, there is a design by the experience of domain experts. For example, Bau et al. [2] used domain ontology and rule reasoning to construct a 
TABLE 1: Utilization of antidiabetic medications from 1998 to 2013.

\begin{tabular}{|c|c|c|c|c|}
\hline Authors & (Publication year) title & $\begin{array}{c}\text { Source period } \\
\text { (year) }\end{array}$ & Country & Antidiabetic medications \\
\hline Chang et al. [15] & $\begin{array}{l}\text { (2012) } \\
\text { National trends in antidiabetic } \\
\text { treatment in Taiwan, 2000-2009 }\end{array}$ & $2000-2009$ & Taiwan & $\begin{array}{l}\text { Biguanides, SU, Meglitinides, } \\
\text { TZDs, } \alpha \text {-glucosidase, } \\
\text { DPP-4, insulin }\end{array}$ \\
\hline Abdelmoneim et al. [20] & $\begin{array}{l}\text { Use patterns of antidiabetic regimens } \\
\text { by patients with type } 2 \text { diabetes }\end{array}$ & $1998-2010$ & Canada & $\begin{array}{l}\text { Biguanides, SU, Meglitinides, } \\
\text { TZDs, } \alpha \text {-glucosidase, insulin }\end{array}$ \\
\hline Kohro et al. [17] & $\begin{array}{c}\text { Trends in antidiabetic prescription } \\
\text { patterns in Japan from } 2005 \text { to } 2011 \text {-impact } \\
\text { of the introduction of dipeptidyl } \\
\text { peptidase- } 4 \text { inhibitors }\end{array}$ & $2005-2011$ & Japan & $\begin{array}{l}\text { Biguanides, SU, Meglitinides, } \\
\text { TZDs, } \alpha \text {-glucosidase, } \\
\text { DPP-4, GLP-1, insulin }\end{array}$ \\
\hline Hsu et al. [21] & $\begin{array}{l}\text { (2015) } \\
\text { Utilization of oral antidiabetic medications } \\
\text { in Taiwan following strategies to promote } \\
\text { access to medicines for chronic diseases } \\
\text { in community pharmacies }\end{array}$ & $2001-2010$ & Taiwan & $\begin{array}{l}\text { Biguanides, SU, Meglitinides, } \\
\text { TZDs, } \alpha \text {-glucosidase, } \\
\text { DPP-4, GLP-1 }\end{array}$ \\
\hline Rafaniello et al. [18] & $\begin{array}{l}\text { Trends in the prescription of antidiabetic } \\
\text { medications from } 2009 \text { to } 2012 \text { in a general } \\
\text { practice of Southern Italy: a population-based study }\end{array}$ & 2009-2012 & Italy & $\begin{array}{l}\text { Biguanides, SU, Meglitinides, } \\
\text { TZDs, } \alpha \text {-glucosidase, } \\
\text { DPP-4, GLP-1, insulin }\end{array}$ \\
\hline Ko et al. [19] & $\begin{array}{l}\text { (2016) } \\
\text { Trends of antidiabetic drug use in adult } \\
\text { Type } 2 \text { diabetes in Korea in 2002-2013: } \\
\text { nationwide population-based cohort study }\end{array}$ & $2002-2013$ & Korea & $\begin{array}{l}\text { Biguanides, SU, Meglitinides, } \\
\text { TZDs, } \alpha \text {-glucosidase, } \\
\text { DPP-4, insulin }\end{array}$ \\
\hline Ou et al. [16] & $\begin{array}{l}\text { (2016) } \\
\text { Recent trends in the use of antidiabetic } \\
\text { medications from } 2008 \text { to 2013: a nationwide } \\
\text { population-based study from Taiwan }\end{array}$ & $2008-2013$ & Taiwan & $\begin{array}{l}\text { Biguanides, SU, Meglitinides, } \\
\text { TZDs, } \alpha \text {-glucosidase, } \\
\text { DPP-4, GLP-1, insulin }\end{array}$ \\
\hline
\end{tabular}

SU: sulfonylureas; TZDs: thiazolidinediones; DPP-4: dipeptidyl peptidase-4; SGLT2: sodium-glucose cotransporter 2; GLP-1: glucagon-like peptide 1.

CDSS for diabetic patients undergoing surgery. They have three main classes in this ontology: disease, management, and patient. The disease class consists of diabetes and comorbidity information. The management class consists of anesthesia, capillary glucose tests, control of DM, medication, no medication, and water restriction information. The patient class consists of the patient clinical profile. The system constructs a clinical decision support system (CDSS) for undergoing surgery based on domain ontology and rules reasoning in the setting of hospitalized diabetic patients. However, the ontology knowledge is built on the experience of clinical practitioners, so it is hard to update these ontologies knowledge when there is a new clinical guideline.

Sherimon and Krishnan [11] had proposed an OntoDiabetic system which an ontology-based clinical decision support system for risk analysis and prediction of diabetes mellitus. The system consists of two main ontologies: the diabetic patient clinical analysis ontology and the semantic profile. The diabetic patient clinical analysis ontology and reasoning rules encapsulate the NICE (National Institute for Health and Care Excellence) guidelines. The OntoDiabetic system calculates the score and predicts the risk of diabetic patients due to smoking, alcohol, physical activity, and sexual and cardiovascular diseases that mainly affect diabetes. Lots of effort was made on OntoDiabetic. What seems to be lacking, however, is that the system cannot provide antidiabetic medications suggestion.

Because there are many types of antidiabetic medications, they need to obtain permission from the government. Although the American Diabetes Association (ADA) and the European Association for the Study of Diabetes (EASD) statements $[13,14]$ provide 12 types of antidiabetic medications, not every drug can be used. Table 1 shows eight antidiabetic medications which are commonly used in Japan, Korea, Canada, Italy, and Taiwan from 1998 to 2013 [15-21].

Although a number of researchers have considered the positive potential of CDSS, they did not consider patients' characteristics. For example, at the "patients' attitude" factor, if the patient has highly motivated or excellent self-care capacities, it can use active treatment strategies or $\mathrm{HbAlc}$ targets. To solve this problem, we proposed a solution in our previous research which adopted the ADA and the EASD standards who published an updated position statement on the management of hyperglycemia in type 2 diabetes to build $H b A 1 c$ target inference module as well as drug knowledge ontology [22]. The system 


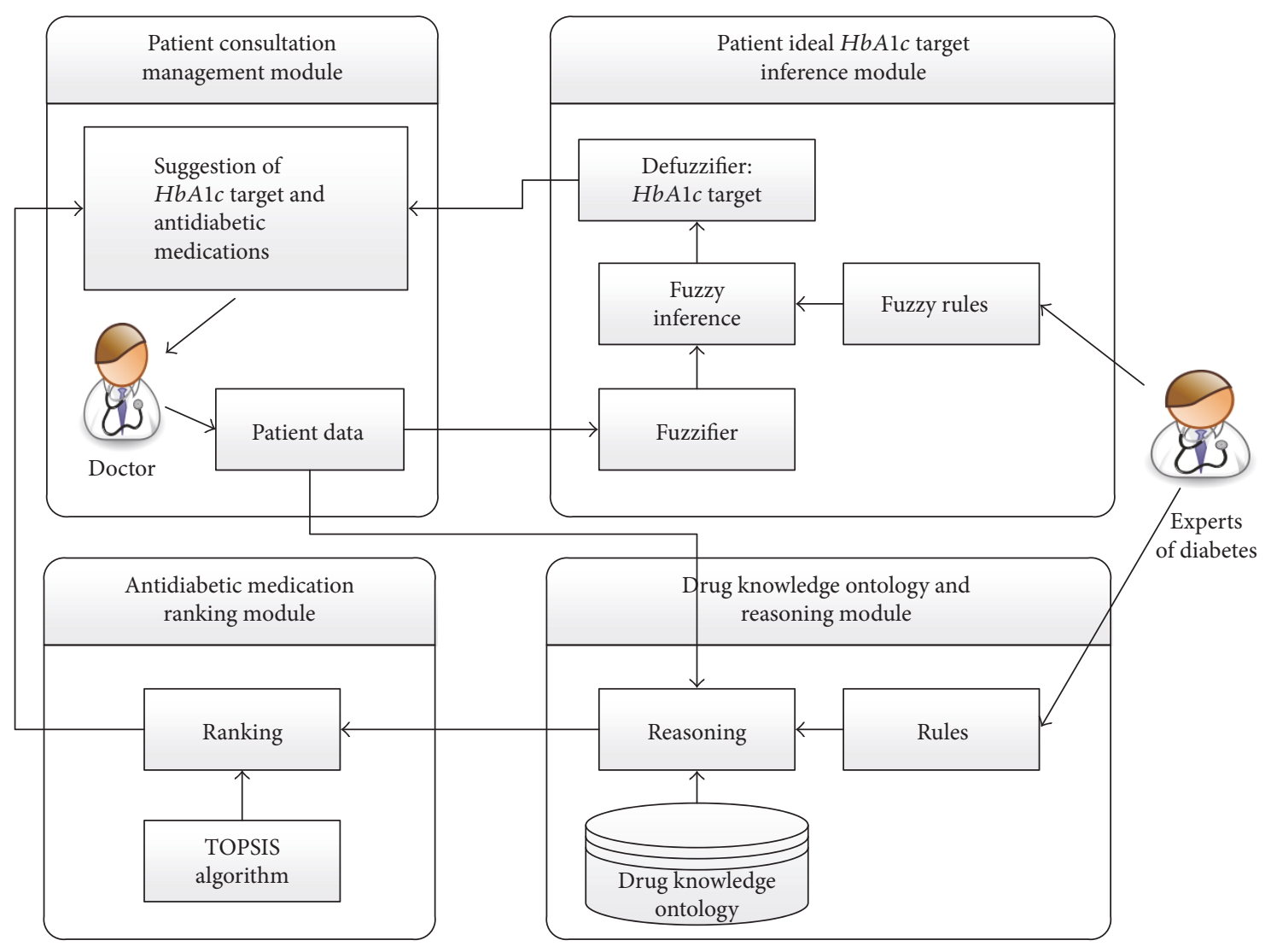

FIGURE 1: The recommendation system.

combines fuzzy logic and ontology reasoning to propose an antidiabetic medication recommendation system for patients with T2DM.

In this paper, we will further consider the safety and positivity of $H b A 1 c$ target, and the priority of antidiabetic medication. We use the antidiabetic medication profiles, which are presented by the American Association of Clinical Endocrinologists (AACE) and American College of Endocrinology (ACE) in 2016 [23]. Based on the antidiabetic medication profiles, we used the Technique for Order of Preference by Similarity to Ideal Solution (TOPSIS) to calculate the relative closeness to the ideal solution and thus determined the ranking of antidiabetic medications.

\section{Materials and Methods}

The recommendation system consists of four modules: the patient consultation management, the patient perfect $\mathrm{HbAlc}$ target inference, the drug knowledge ontology and reasoning, and antidiabetic medication ranking modules. The framework of the recommendation system is shown in Figure 1.

The first step, the "patient consultation management module," provides a user interface to the clinical doctor. So, the clinical doctor can input patient's data in the user interface. Those patient's data will be provided to the other two modules. The second step, the "patient ideal $\mathrm{HbA1c}$ target inference module," will use fuzzy technology to infer the patient's individualization HbAlc target. The third step, the "drug knowledge ontology and reasoning module," will recommend antidiabetic medications for the patient. The fourth step, the "antidiabetic medications ranking module," will use TOPSIS technology to calculate the relative closeness to the ideal solution and thus determine the ranking of antidiabetic medications. In this system, the experts of diabetes decided the fuzzy rules and ontology reasoning rules.

2.1. Patient Consultation Management Module. The patient consultation management module requires the patients' data which is also necessary for the other modules. The modulation of the intensiveness of glucose lowering therapy in T2DM is according to the ADA and the EASD position statement [14]. The sufficient communication between the clinical doctor and the patient is also necessary to evaluate seven factors. They are (1) the risks associated with hypoglycemia and other drug adverse effects, (2) disease duration, (3) life expectancy, (4) important comorbidities, (5) established vascular complications, (6) patient attitude and expected treatment efforts, and (7) resources and support system. Each of the seven factors has five levels measured by integers 0 to 4 . The clinical doctor also needs to record adverse drug reactions (ADRs) and individual history of diseases.

2.2. Patient Ideal HbA1c Target Inference Module. The main functional modules include fuzzifier, fuzzy rules, fuzzy inference, and defuzzier. There are seven inputs, namely, $x_{1}, \ldots$, $x_{7}$, for fuzzy logic and the input factors are divided into five 
TABLE 2: Names of membership functions, input, and output variables.

\begin{tabular}{|c|c|c|c|c|}
\hline Variable & Name & Function 1 & Function 2 & Function 3 \\
\hline$x_{1}$ & Risks potentially associated with hypoglycemia and other drug adverse effects & Low & High & - \\
\hline$x_{2}$ & Disease duration & Newly Diagnosed & Long Standing & - \\
\hline$x_{3}$ & Life expectancy & Long & Short & - \\
\hline$x_{4}$ & Important comorbidities & Absent & FewOrMild & Severe \\
\hline$x_{5}$ & Established vascular complications & Absent & FewOrMild & Severe \\
\hline$x_{6}$ & Patient attitude and expected treatment efforts & $\begin{array}{c}\text { Highly } \\
\text { Motivated }\end{array}$ & Less Motivated & - \\
\hline$x_{7}$ & Resources and support system & Readily Available & Limited & - \\
\hline$z$ & $H b A 1 c$ & More Stringent & Mild Stringent & Less Stringent \\
\hline
\end{tabular}

levels, ranging from integers 0 to 4 . The output value $z$ is the ideal patient $H b A 1 c$ target level which considers individual differences. The American Association of Clinical Endocrinologists (AACE) and American College of Endocrinology (ACE) suggested $H b A 1 c$ below 6.5\% [24], but patientcentered care is needed to consider the patient's characteristics to set the patient's $H b A 1 c$ target. So, the output $z$ represents the ideal $H b A 1 c$ target, which varies between $6.5 \%$ and $9.0 \%$.

The definition of membership functions is according to the ADA and EASD position statement [14], for example, the "Risks potentially associated with hypoglycemia and other drug adverse effects" can have two levels: "Low" or "High." So, $x_{1}$ has two membership functions: $\operatorname{Low}\left(x_{1}\right)$ and $\operatorname{High}\left(x_{1}\right)$. The names of the membership functions as well as input and output variables are shown in Table 2 . To get the acceptable results, the endocrinologist who works in Taichung Hospital, Ministry of Health and Welfare, has established virtual patients' data and use the FuzzyLite [25] to trial and adjust the parameters of membership functions. Through the sufficient experience of the clinician, the system has better results.

Figure 2 shows the corresponding membership function for $x_{1}$ factor, and the membership function for $\operatorname{Low}\left(x_{1}\right)$ and $\operatorname{High}\left(x_{1}\right)$ is a trapezoid. Because the $x_{2}, x_{3}, x_{6}$, and $x_{7}$ also can be divided into two functions, their membership functions are the same as that for $x_{1}$. Figure 3 shows the corresponding membership function for $x_{4}$ factor, and the membership function for $\operatorname{Absent}\left(x_{4}\right)$ and $\operatorname{Severe}\left(x_{4}\right)$ is trapezoidal while FewOrMild $\left(x_{4}\right)$ is triangular. Because the $x_{5}$ also can be divided into three functions, $x_{5}$ membership functions are the same as $x_{4}$. The domain knowledge of the defining membership functions is derived from doctors' reports. Figure 4 shows the corresponding membership function for $z$ and the membership functions for MoreStringent $(z)$ and LessStringent $(z)$ are trapezoidal while that for MildStrin$\operatorname{gent}(z)$ is triangular.

The second step is to apply inputs to the fuzzy rules. The fuzzy inference will then stipulate what action will be taken for each combination of sets of memberships. To evaluate the effectiveness of the system, we developed two kinds of fuzzy rule methods. The primary consideration for the first method is relative safety of treatment so we label it "fuzzy safety rules." The second method is to consider the

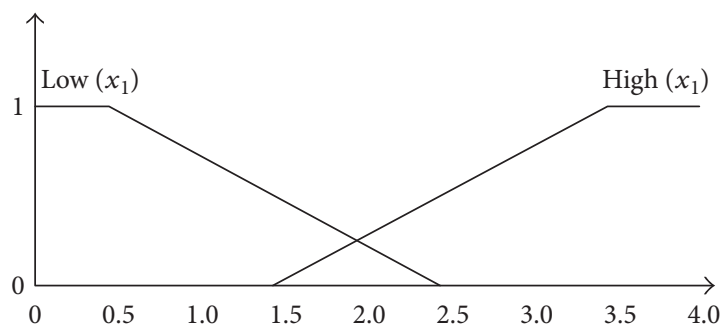

FIgURE 2: Membership functions of $x_{1}$ factor.

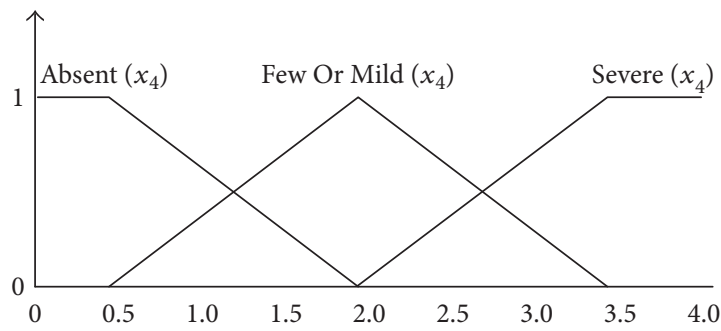

Figure 3: Membership functions of $x_{4}$ factor.

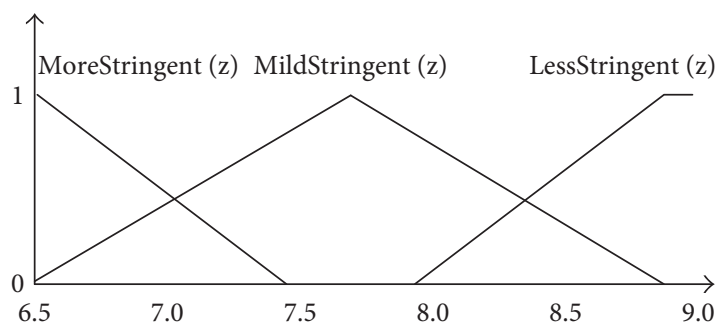

FIGURE 4: Membership functions of $z$ factor.

performance of more positive treatment; we mark it "fuzzy positivity rules."

2.2.1. Method 1: Fuzzy Safety Rules. The number of fuzzy rules depends on several input factors. For example, if the clinical doctor inputs $\times 1, \times 2$, and $\times 4$ values, the fuzzy rules will consist of 12 individual rules. Because $\times 1$ has two membership functions (low and high), $\times 2$ has two membership functions (Newly Diagnosed and Long Standing), and $\times 4$ 
TABLE 3: Example of fuzzy safety rules table.

\begin{tabular}{lcccc}
\hline Rule & $x_{1}$ & $x_{2}$ & $x_{4}$ & $z$ \\
\hline 1 & Low & Newly Diagnosed & Absent & More Stringent \\
2 & Low & Newly Diagnosed & FewOrMild & Mild Stringent \\
3 & Low & Newly Diagnosed & Severe & Less Stringent \\
4 & Low & Long Standing & Absent & Less Stringent \\
5 & Low & Long Standing & FewOrMild & Less Stringent \\
6 & Low & Long Standing & Severe & Less Stringent \\
7 & High & Newly Diagnosed & Absent & Less Stringent \\
8 & High & Newly Diagnosed & FewOrMild & Less Stringent \\
9 & High & Newly Diagnosed & Severe & Less Stringent \\
10 & High & Long Standing & Absent & Less Stringent \\
11 & High & Long Standing & FewOrMild & Less Stringent \\
12 & High & Long Standing & Severe & Less Stringent \\
\hline
\end{tabular}

has three membership functions (Absent, Few or Mild, and Severe). Based on individual experts' experience and intuition, the fuzzy rules table is shown in Table 3 . Rule 1 indicates that if $x_{1}$ is low and $x_{2}$ is newly diagnosed, and $x_{4}$ is absent, then $z$ is more stringent. Rule 2 states that if $x_{1}$ is low and $x_{2}$ is newly diagnosed, and $x_{4}$ is few or mild, then $z$ is mild stringent. Otherwise, the output $z$ is less stringent in rules $3-12$ because $x_{1}$ is high, or $x_{2}$ is long standing, or $x_{4}$ is severe.

2.2.2. Method 2: Fuzzy Positivity Fuzzy Rules. Table 4 shows the fuzzy positivity rules. Rules 1-5 indicate that if one of the $\left\{x_{1}, x_{2}, x_{3}, x_{4}, x_{5}\right\}$ input variables is High/LongStanding/Short/Severe/Severe, then $\mathrm{HbA1c}$ is less stringent. Rules 6-9 indicate that if one of the $\left\{x_{2}, x_{3}, x_{6}, x_{7}\right\}$ input variables is Newly-Diagnosed/Long/Highly-Motivated/Readily-Available, then $\mathrm{HbAlc}$ is more stringent. Rule 10 indicates that if the "Risks-Of-Hypoglycemia-or-Drug-Effects" are low and "Important-Comorbidities" and "Established-VascularComplications" are absent, then $\mathrm{HbAlc}$ is More-Stringent. Rules 11 and 12 show that if "Important-Comorbidities" or "Established-Vascular-Complications" are Few-orMild, then $\mathrm{HbA1c}$ is Mild-Stringent. Rule 13 states that if both of "Important-Comorbidities" and "EstablishedVascular-Complications" are "Few-or-Mild," then $\mathrm{HbA} 1 \mathrm{c}$ is Less-Stringent.

Finally, for both fuzzy safety rules and fuzzy positivity rules, the system uses the mean of maximum (MOM) to perform defuzzification.

2.3. Drug Knowledge Ontology and Reasoning Module. Protégé and WebProtégé are free software programs for building ontology knowledge solutions $[6,26]$. Further, "Jena" is the Java rule-based inference engine developed by Apache Software Foundation [27]. We use WebProtégé to build drug knowledge, and the web-based interface is an easy interface with a diabetes diplomate. When the ontology build is complete, we use Jena to evaluate the antidiabetic medications reasoning module. The details are as follows.

2.3.1. Drug Knowledge Ontology. According to an update of the position statement published by the ADA and the EASD
$[13,14]$, we created a glucose-lowering agents ontology. Table 5 shows the classes and the descriptions of their concepts in the domain knowledge. Classes can contain individual objects called "instances." Table 6 presents the defined properties in the ontology. Object properties represent relationships between two instances and each property has a domain and range. After classes and object properties are created, we build glucose-lowering agent instances based on the ADA and the EASD's position statement on the management of hyperglycemia in type 2 diabetes. Figure 5 shows "Biguanides" instances of the "GlucoseLowering_Agents" class and Figure 6 shows an example of patient_1's instance.

2.3.2. Antidiabetic Medications Reasoning Module. Jena is a free and open source Java framework for building semantic web and inference applications [27]. The Jena inference engines support the use of Jena rules to infer from instance data and class descriptions.

Jena is a rule inference engine running on the Java platform. This study developed Jena rules for reasoning which Glucose-Lowering_Agents are not suitable for patients. Table 7 shows the rules described as follows:

Rule 1: If patients have a history of disease which is related to the disadvantages of Glucose-Lowering_Agents, the Glucose-Lowering_Agents are not recommended.

Rule 2: If patients have adverse drug reactions (ADRs), the ADRs are not recommended.

When the system removes some antidiabetic medications, the system can determine other antidiabetic medications. For example, patient_1 has a history of “increasing_LDL-C" and "Edema." TZDs has both disadvantages, "increasing_LDL-C" and "Edema," one of SGLT2's disadvantages is "increasing_LDL-C." By Rule 1, TZDs and SGLT2 will not be recommended to patient_1. patient_1 also has ADRs with GLP-1. Thus, by Rule 2, GLP-1 will not be recommended to patient_1. This system provides seven common antidiabetic medications in Taiwan which include Biguanides (Metformin), Sulfonylureas (SU), TZDs, DPP-4, SGLT2, GLP-1, and Insulin. When TZDs, SGLT2, and GLP-1 are not recommended to patient_1, Biguanides (Metformin), DPP-4, Sulfonylureas (SU), and Insulin are recommended.

2.4. Define Risk of Antidiabetic Medications. The American Association of Clinical Endocrinologists (AACE) and American College of Endocrinology (ACE) published an algorithm for determining glycemic control in 2009 [28]. The comprehensive diabetes management algorithm was updated in 2013, 2015, and 2016 [23, 24, 29-31]. One significant contribution was the presentation of antidiabetic medication profiles. It shows each drug's properties considered for patients.

According to the antidiabetic medication profiles, we convert seven traditional antidiabetic drugs to present the antidiabetic medication risk values. Table 8 shows the risks 
TABLE 4: Example of fuzzy positivity rules table.

\begin{tabular}{|c|c|}
\hline Rule & Function \\
\hline 1 & If (Risks-Of-Hypoglycemia-or-Drug-Effects is High) then (HbA1c is Less-Stringent) \\
\hline 2 & If (Disease-Duration is Long-Standing) then ( $H b A 1 c$ is Less-Stringent) \\
\hline 3 & If (Life-Expectancy is Short) then ( $H b A 1 c$ is Less-Stringent) \\
\hline 4 & If (Important-Comorbidities is Severe) then ( $H b A 1 c$ is Less-Stringent) \\
\hline 5 & If (Established-Vascular-Complications is Severe) then ( $H b A 1 c$ is Less-Stringent) \\
\hline 6 & If (Disease-Duration is Newly-Diagnosed) then ( $H b A 1 c$ is More-Stringent) \\
\hline 7 & If (Life-Expectancy is Long) then ( $H b A 1 c$ is More-Stringent) \\
\hline 8 & If (Patient-Attitude is Highly-Motivated) then ( $\mathrm{HbAlc}$ is More-Stringent) \\
\hline 9 & If (Resources-and-Support-System is Readily-Available) then ( $H b A 1 c$ is More-Stringent) \\
\hline 10 & $\begin{array}{l}\text { If (Risks-Of-Hypoglycemia-or-Drug-Effects is Low) and (Important-Comorbidities is Absent) and } \\
\text { (Established-Vascular-Complications is Absent) then (HbAlc is More-Stringent) }\end{array}$ \\
\hline 11 & If (Important-Comorbidities is Few-or-Mild) then ( $H b A 1 c$ is Mild-Stringent) \\
\hline 12 & If (Established-Vascular-Complications is Few-or-Mild) then (HbAlc is Mild-Stringent) \\
\hline 13 & $\begin{array}{l}\text { If (Important-Comorbidities is Few-or-Mild and (Established-Vascular-Complications is Few-or-Mild) } \\
\text { then ( } \mathrm{HbAlc} \text { is Less-Stringent) }\end{array}$ \\
\hline
\end{tabular}

TABLE 5: Classes in the domain ontology.

\begin{tabular}{lr}
\hline Class & Description \\
\hline Glucose-Lowering_Agents & $\begin{array}{c}\text { Concepts are glucose-lowering drugs. Ontology content is } \\
\text { based on the ADA/EASD's position statement on management } \\
\text { of hyperglycemia in type 2 diabetes to be established } \\
\text { Concepts about glucose-lowering advantages }\end{array}$ \\
$\begin{array}{l}\text { Glucose-Lowering_Advantages } \\
\text { Glucose-Lowering_Cellular_mechanisms } \\
\text { Glucose-Lowering_Compounds } \\
\begin{array}{l}\text { Glucose-Lowering_Cost } \\
\text { Glucose-Lowering_Disadvantages }\end{array} \\
\text { Glucose-Lowering_Primary_physiological_actions about glucose-lowering cellular mechanisms } \\
\text { Concepts about glucose-lowering compounds } \\
\text { Concepts about glucose-lowering cost } \\
\text { Concepts about glucose-lowering disadvantages }\end{array}$ \\
$\begin{array}{l}\text { Concepts about glucose-lowering primary physiological actions } \\
\text { Concepts about patient's profile, the properties include patient's } \\
\text { adverse drug reactions (ADRs) and history of diseases }\end{array}$ \\
\hline
\end{tabular}

TABLE 6: Defined properties in the ontology.

\begin{tabular}{lccc}
\hline Property name & Property type & Domain & Range \\
\hline has_Advantages & Object & Glucose-Lowering_Agents & Glucose-Lowering_Advantages \\
has_Cellular_mechanisms & Object & Glucose-Lowering_Agents & Glucose-Lowering_Cellular mechanisms \\
has_Compounds & Object & Glucose-Lowering_Agents & Glucose-Lowering_Compounds \\
has_Cost & Object & Glucose-Lowering_Agents & Glucose-Lowering_Cost \\
has_Disadvantages & Object & Glucose-Lowering_Agents & Glucose-Lowering_Disadvantages \\
has_Primary_physiological_actions & Object & Glucose-Lowering_Agents & Glucose-Lowering_Primary physiological_actions \\
has_History_of_Diseases & Object & Patients & Glucose-Lowering_Disadvantages \\
has_Adverse & Object & Patients & Glucose-Lowering_Agents \\
Drug_Reactions & Object & Patients & Glucose-Lowering_Agents \\
Not_recommended & Data & Patients & xsd: string \\
ID_No & & &
\end{tabular}

of antidiabetic medications. The risk value of "Few adverse events of possible benefits" is 1 . The risk value of "Neutral" is 3 and "Use with caution" is 5. Finally, the "Likelihood of adverse effects" is defined as a risk value of 7. Of note, we added "cost" property values according to the position statement of the ADA and the EASD [14]. If cost is "Low," the 


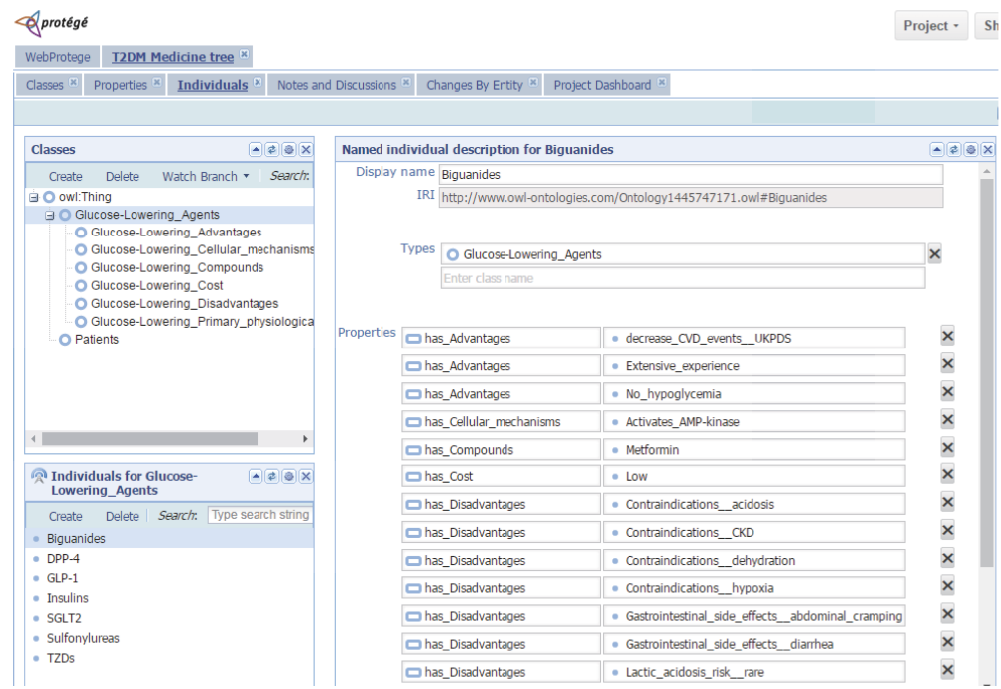

Figure 5: "Biguanides" instances of the "Glucose-Lowering_Agents" class.

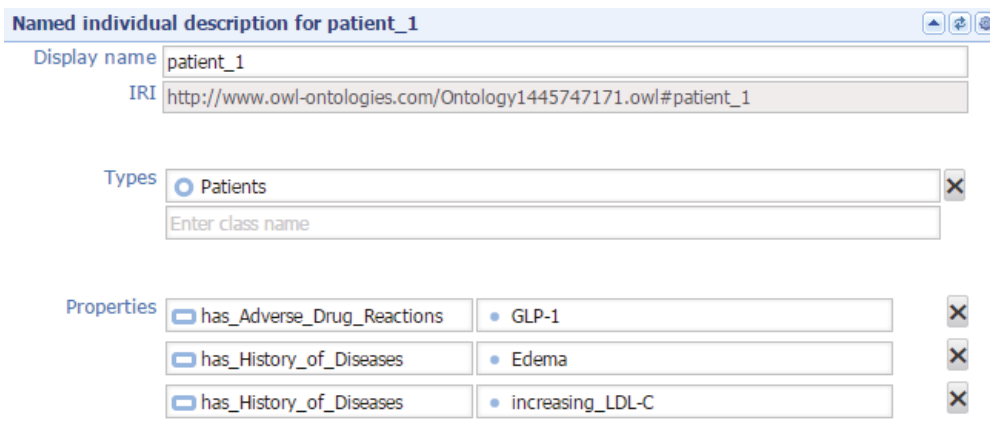

FIGURE 6: Example of "patient_1."

TABLE 7: Example of ontology reasoning rules table.

\begin{tabular}{|c|c|}
\hline No. & Rule \\
\hline (1) & $\begin{array}{c}\text { (?x rdf:type http://www.owl-ontologies.com/Ontology1445747171.owl\#Patients) } \\
\text { (?x http://www.owl-ontologies.com/Ontology1445747171.owl\#has_History_of_Diseases ?y) } \\
\text { (?n rdf:type http://www.owl-ontologies.com/Ontology1445747171.owl\#Glucose-Lowering_Agents) } \\
\text { (?n http://www.owl-ontologies.com/Ontology1445747171.owl\#has_Disadvantages ?y) -> } \\
\text { (?x http://www.owl-ontologies.com/Ontology1445747171.owl\#Not_recommand ?n) }\end{array}$ \\
\hline (2) & $\begin{array}{l}\text { (?x rdf:type http://www.owl-ontologies.com/Ontology1445747171.owl\#Patients) } \\
\text { (?x http://www.owl-ontologies.com/Ontology1445747171.owl\#has_Adverse_Drug_Reactions ?n) -> } \\
\text { (?x http://www.owl-ontologies.com/Ontology1445747171.owl\#Not_recommand ?n) }\end{array}$ \\
\hline
\end{tabular}

property value is 1 . If cost is "High," the property value is 3. In this case, there are some antidiabetic medications like "Meglitinides," " $\alpha$-glucosidase inhibitors" whose cost is "Moderate" so the property value is 2 . However, these antidiabetic medications are not popular in Taiwan, so they do show in Table 8 .

2.5. TOPSIS Multicriteria Decision Analysis. When the risk of antidiabetic medications is known, we can use it to calculate the antidiabetic medication recommended priority. The Technique for Order of Preference by Similarity to
Ideal Solution (TOPSIS) implements a multicriteria decision which was developed by Hwang and Yoon in 1981 [4, 32-34]. TOPSIS was employed to decide antidiabetic medications ranking.

In previous calculations, the system recommended MET (Biguanides), DPP-4, SU (Sulfonylureas), and Insulin for patient_1. Table 9 shows the risk of antidiabetic medications and cost for patient_1. We will use the risk data of Table 9 as an example to explain the TOPSIS method.

The TOPSIS process of patient_1 was carried out as follows. 
TABLE 8: Risk of antidiabetic medications and cost.

\begin{tabular}{lccccccc}
\hline \multirow{2}{*}{ Properties } & \multicolumn{7}{c}{ Antidiabetic medications } \\
& MET & GLP-1 & SGLT2 & DPP-4 & TZD & SU & Insulin \\
\hline Hypo & 3 & 3 & 3 & 3 & 3 & 7 & 7 \\
Weight & 1 & 1 & 1 & 3 & 5 & 7 & 7 \\
Renal/GU & 7 & 7 & 5 & 3 & 3 & 7 & 7 \\
GI Sx & 5 & 5 & 3 & 3 & 3 & 3 & 3 \\
CHF & 3 & 3 & 3 & 3 & 5 & 3 & 3 \\
CVD & 1 & 3 & 3 & 3 & 3 & 5 & 3 \\
Bone & 3 & 3 & 3 & 3 & 5 & 3 & 3 \\
Cost & 1 & 3 & 3 & 3 & 1 & 1 & 3 \\
\hline
\end{tabular}

MET: metformin (Biguanides); SU: sulfonylureas; Hypo: hypoglycemia; GU: genitourinary; GI Sx: glycemic index symptom; CHF: congestive heart failure; CVD: cardiovascular diseases.

Step 1: Create the Decision Matrix. Create an evaluation matrix consisting of $m$ alternatives and $n$ criteria with the intersection of each alternative and criteria are given as $A$.

$$
R_{4 \times 8}=\left[\begin{array}{cccc}
0.279 & 0.096 & 0.560 & 0.693 \\
0.279 & 0.289 & 0.240 & 0.416 \\
0.650 & 0.674 & 0.560 & 0.416 \\
0.650 & 0.674 & 0.560 & 0.416
\end{array}\right.
$$

Step 3: Determine the Weight. Determine the weight $W$ with the antidiabetic medication's risk properties and cost. The

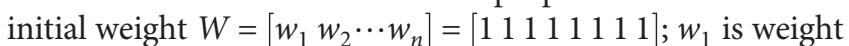
of the Hypo property; $w_{2}$ is weight of Weight property; $w_{3}$ is weight of Renal/GU property; $w_{4}$ is weight of GI Sx property; $w_{5}$ is weight of CHF property; $w_{6}$ is weight of CVD property; $w_{7}$ is weight of Bone property; and $w_{8}$ is weight of Cost property.

In this case, patient_1 has a history of "Edema" and "increasing LDL-C." Because "Edema" is relative to $\mathrm{CHF}$, the $w_{5}$ is set to 2 , and "increasing LDL-C" is relative to CVD, the $w_{6}$ set to 2 . The weight $W$ of patient_1 is shown as follows:

$$
\begin{gathered}
A=\left[A_{i j}\right]_{m \times n}=\left[\begin{array}{ccc}
a_{11} & \cdots & a_{1 n} \\
\vdots & \ddots & \vdots \\
a_{m 1} & \cdots & a_{m n}
\end{array}\right], \\
i=1,2, \ldots, m, j=1,2, \ldots, n .
\end{gathered}
$$

For example, the decision matrix of Table 9 is

$$
A_{4 \times 8}=\left[\begin{array}{cccccccc}
3 & 1 & 7 & 5 & 3 & 1 & 3 & 1 \\
3 & 3 & 3 & 3 & 3 & 3 & 3 & 3 \\
7 & 7 & 7 & 3 & 3 & 5 & 3 & 1 \\
7 & 7 & 7 & 3 & 3 & 3 & 3 & 3
\end{array}\right] .
$$

Step 2: Construct Normalized Decision Matrix. The matrix A is then normalized to form the matrix:

$$
R=\left[R_{i j}\right]_{m \times n}=\left[\begin{array}{ccc}
r_{11} & \cdots & r_{1 n} \\
\vdots & \ddots & \vdots \\
r_{m 1} & \cdots & r_{m n}
\end{array}\right]
$$

where $r_{i j}=a_{i j} /\left(\sqrt{\sum_{k=1}^{m} a_{k j}^{2}}\right), i=1,2, \ldots, m, j=1,2, \ldots, n$.

$$
\left.\begin{array}{llll}
0.500 & 0.151 & 0.500 & 0.224 \\
0.500 & 0.452 & 0.500 & 0.671 \\
0.500 & 0.754 & 0.500 & 0.224 \\
0.500 & 0.452 & 0.500 & 0.671
\end{array}\right]
$$

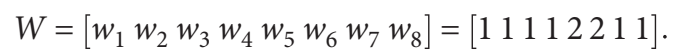

Step 4: Construct the Weighted Normalized Decision Matrix. Calculate the weighted normalized decision matrix $V$ :

$$
V=\left[V_{i j}\right]_{m \times n}=\left[\begin{array}{ccc}
v_{11} & \cdots & v_{1 n} \\
\vdots & \ddots & \vdots \\
v_{m 1} & \cdots & v_{m n}
\end{array}\right]
$$

where $v_{i j}=w_{j} r_{i j}, i=1,2, \ldots, m$, and $j=1,2, \ldots, n$.

$$
V_{4 \times 8}=\left[\begin{array}{cccccccc}
0.279 & 0.096 & 0.560 & 0.693 & 1.000 & 0.302 & 0.500 & 0.224 \\
0.279 & 0.289 & 0.240 & 0.416 & 1.000 & 0.905 & 0.500 & 0.671 \\
0.650 & 0.674 & 0.560 & 0.416 & 1.000 & 1.508 & 0.500 & 0.224 \\
0.650 & 0.674 & 0.560 & 0.416 & 1.000 & 0.905 & 0.500 & 0.671
\end{array}\right] .
$$


Step 5: Determine the Ideal and Negative Ideal Solutions. Determine the ideal solution $A^{*}$ and the negative ideal solution $A^{-}$:

$$
A^{*}=\left\{V_{1}^{*}, V_{2}^{*}, \ldots, V_{n}^{*}\right\}
$$

where $V_{j}^{*}=\min _{i} V_{i j}, i=1,2, \ldots, m$.

$$
A^{-}=\left\{V_{1}^{-}, V_{2}^{-}, \ldots, V_{n}^{-}\right\}
$$

where $V_{j}^{-}=\max _{i} V_{i j}, i=1,2, \ldots, m$.

$$
\begin{aligned}
A^{*} & =\left(\min _{i} v_{i 1}, \min _{i} v_{i 2}, \min _{i} v_{i 3}, \min _{i} v_{i 4}, \min _{i} v_{i 5}, \min _{i} v_{i 6}, \min _{i} v_{i 7}, \min _{i} v_{i 8}\right) \\
& =(0.279,0.096,0.240,0.416,1.000,0.302,0.500,0.224), \\
A^{-} & =\left(\max _{i} v_{i 1}, \max _{i} v_{i 2}, \max _{i} v_{i 3}, \max _{i} v_{i 4}, \max _{i} v_{i 5}, \max _{i} v_{i 6}, \max _{i} v_{i 7}, \max _{i} v_{i 8}\right) \\
& =(0.650,0.674,0.560,0.693,1.000,1.508,0.500,0.671) .
\end{aligned}
$$

Step 6: Calculate the Separation Measures for Each Alternative. Calculate the distance between the target alternative $i$ and ideal alternative $S_{i}^{*}$ and the negative ideal alternative $S_{i}^{-}$:

$$
\begin{aligned}
& S_{i}^{*}=\sqrt{\sum_{j=1}^{n}\left(V_{i j}-V_{j}^{*}\right)^{2}}, \quad i=1,2, \ldots, m, \\
& S_{i}^{-}=\sqrt{\sum_{j=1}^{n}\left(V_{i j}-V_{j}^{-}\right)^{2}}, \quad i=1,2, \ldots, m .
\end{aligned}
$$

From the above formula, the system can find the values of $S_{i}^{*}$ and $S_{i}^{-}$as follows:

$$
\begin{aligned}
& S_{1}^{*}=0.424, \\
& S_{2}^{*}=0.775, \\
& S_{3}^{*}=1.424, \\
& S_{4}^{*}=1.067, \\
& S_{1}^{-}=1.458, \\
& S_{2}^{-}=0.911, \\
& S_{3}^{-}=0.526, \\
& S_{4}^{-}=0.664 .
\end{aligned}
$$

Step 7: Calculate the Relative Closeness to the Ideal Solution $C_{i}^{*}$.

$$
C_{i}^{*}=\frac{S_{i}^{-}}{S_{i}^{*}+S_{i}^{-}}, \quad i=1,2, \ldots, m .
$$

From the above formula, the system will select the options with $C_{i}^{*}$ closest to 1 .

$$
\begin{aligned}
& C_{1}^{*}=0.775, \\
& C_{2}^{*}=0.540, \\
& C_{3}^{*}=0.270, \\
& C_{4}^{*}=0.384 .
\end{aligned}
$$

The results show that the ideal solution $C_{1}^{*}$ of MET is 0.775 , the ideal solution $C_{2}^{*}$ of DPP- 4 is 0.540 , the ideal solution $C_{3}^{*}$ of $\mathrm{SU}$ is 0.270 , and the ideal solution $C_{4}^{*}$ of the Insulin is 0.384 . Because $C_{1}^{*}>C_{2}^{*}>C_{4}^{*}>C_{3}^{*}$, the recommendation priority of antidiabetic medications is MET $>$ DPP-4 > Insulin $>$ SU.

\section{Results}

According to the ADA and the EASD's statement, one of the major changes in treatment options is a new antidiabetic medication "SGLT2" which is added. So, we add "SGLT2" to this experiment. However, "Meglitinides" and " $\alpha$-Glucosidase" have "Frequent dosing schedule" disadvantage, so we exclude those two antidiabetic medications. Finally, this system provides seven common antidiabetic medication choices which include "Biguanides," "SU," “TZDs," "DPP-4," "SGLT2," “GLP-1,” and "Insulin.”

Taichung Hospital is an accredited area hospital in central Taiwan. At the beginning of the system development, the endocrinologist who works in Taichung Hospital set up ten virtual patients' medical data to trial and adjusted clinical decision support system (CDSS). We used Mamdani-type fuzzy inference and mean of maximum (MOM) to perform defuzzification. Table 10 shows the virtual patient's medical data. In Table 10, the $x_{1}, x_{2}, x_{3}, \ldots, x_{7}$, "History of Diseases" and "ADRs" are input variables for diabetes diplomat. The $z$ is the fuzzy inference output of the $H b A 1 c$ target which, respectively, are fuzzy safety rules (Method 1) and fuzzy positivity rules (Method 2). The "Recommend antidiabetic medications" shows the recommended medications for patients and the ranking value.

An attending physician, an endocrinologist, and a resident physician evaluated the decision support system for diabetes. They were direct using the system and evaluation it by their clinical experience. They evaluated the system using a 12-question, 5-point survey, regarding satisfaction degree, perceived usefulness, and behavioral intentions 
TABLE 9: Risk of antidiabetic medications and cost for patient_1.

\begin{tabular}{|c|c|c|c|c|c|c|c|c|}
\hline Antidiabetic medications & Нуро & Weight & Renal/GU & $\begin{array}{l}\text { Proper } \\
\text { GI Sx }\end{array}$ & $\mathrm{CHF}$ & CVD & Bone & Cost \\
\hline MET & 3 & 1 & 7 & 5 & 3 & 1 & 3 & 1 \\
\hline DPP-4 & 3 & 3 & 3 & 3 & 3 & 3 & 3 & 3 \\
\hline SU & 7 & 7 & 7 & 3 & 3 & 5 & 3 & 1 \\
\hline Insulin & 7 & 7 & 7 & 3 & 3 & 3 & 3 & 3 \\
\hline
\end{tabular}

TABLe 10: Ten virtual patients' medical data.

\begin{tabular}{|c|c|c|c|c|c|c|c|c|}
\hline ID & Age & Sex & $\begin{array}{c}x_{1}, x_{2}, x_{3}, x_{4} \\
x_{5}, x_{6}, x_{7}\end{array}$ & has_History of Diseases & has_ADRs & $\begin{array}{c}z \\
(\operatorname{method} 1)\end{array}$ & $\begin{array}{c}z \\
\text { (method 2) } \\
\end{array}$ & $\begin{array}{l}\text { Recommended } \\
\text { antidiabetic medications }\end{array}$ \\
\hline 1 & 73 & Female & $\begin{array}{l}\text { 3, 2, 3, NaN, } \\
\mathrm{NaN} \\
\mathrm{NaN}, \mathrm{NaN}\end{array}$ & $\begin{array}{l}\text { increasing_LDL-C, } \\
\text { Edema }\end{array}$ & GLP-1 & 8.6 & 8.9 & $\begin{array}{l}\text { (1) Biguanides }(0.775) \\
\text { (2) DPP-4 }(0.540) \\
\text { (3) Insulins }(0.384) \\
\text { (4) Sulfonylureas }(0.270)\end{array}$ \\
\hline 2 & 75 & Female & $\begin{array}{l}3,2,4, \mathrm{NaN} \\
\mathrm{NaN} \\
\mathrm{NaN}, \mathrm{NaN}\end{array}$ & $\begin{array}{l}\text { Heart_failure, } \\
\text { increasing_LDL-C }\end{array}$ & $\mathrm{NaN}$ & 8.6 & 9.0 & $\begin{array}{l}\text { (1) Biguanides }(0.788) \\
\text { (2) DPP-4 }(0.549) \\
\text { (3) GLP-1 }(0.536) \\
\text { (4) Insulins }(0.376) \\
\text { (5) Sulfonylureas }(0.248)\end{array}$ \\
\hline 3 & 64 & Female & $\begin{array}{l}\text { 2, } 1,2, \mathrm{NaN} \\
\mathrm{NaN} \\
\mathrm{NaN}, \mathrm{NaN}\end{array}$ & $\begin{array}{l}\text { Bone_fractures, } \\
\text { increasing_LDL-C }\end{array}$ & $\mathrm{NaN}$ & 6.9 & 6.6 & $\begin{array}{l}\text { (1) Biguanides }(0.788) \\
\text { (2) DPP-4 }(0.549) \\
\text { (3) GLP-1 }(0.536) \\
\text { (4) Insulins }(0.376) \\
\text { (5) Sulfonylureas }(0.248)\end{array}$ \\
\hline 4 & 76 & Female & $\begin{array}{l}4,3,3,2,1 \\
\text { NaN, NaN }\end{array}$ & $\begin{array}{l}\text { increasing_LDL-C, } \\
\text { Contraindications_CKD }\end{array}$ & DPP-4 & 8.8 & 7.8 & $\begin{array}{l}\text { (1) GLP-1 }(0.631) \\
\text { (2) Insulins }(0.445) \\
\text { (3) Sulfonylureas }(0.369)\end{array}$ \\
\hline 5 & 61 & Female & $\begin{array}{l}4,3,2,3,2 \\
\text { NaN, NaN }\end{array}$ & $\begin{array}{c}\text { Heart_failure, } \\
\text { increasing_LDL-C, } \\
\text { Contraindications_CKD, } \\
\text { Weight_gain }\end{array}$ & $\mathrm{NaN}$ & 8.6 & 7.8 & $\begin{array}{l}\text { (1) GLP-1 }(0.534) \\
\text { (2) DPP-4 (0.466) }\end{array}$ \\
\hline 6 & 64 & Female & $\begin{array}{l}2,1,1, \mathrm{NaN} \\
\mathrm{NaN}, 2, \mathrm{NaN}\end{array}$ & $\mathrm{NaN}$ & $\mathrm{NaN}$ & 6.9 & 6.6 & $\begin{array}{l}\text { (1) Biguanides }(0.731) \\
\text { (2) SGLT2 }(0.648) \\
\text { (3) DPP-4 }(0.619) \\
\text { (4) GLP-1 }(0.586) \\
\text { (5) TZDs }(0.549) \\
\text { (6) Sulfonylureas }(0.377) \\
\text { (7) Insulins }(0.365)\end{array}$ \\
\hline 7 & 62 & Male & $\begin{array}{l}2,2,3, \mathrm{NaN} \\
\mathrm{NaN}, 3,1\end{array}$ & $\begin{array}{c}\text { Gastrointestinal_side_effects_ } \\
\text { abdominal_cramping, } \\
\text { increasing_LDL-C }\end{array}$ & $\mathrm{NaN}$ & 8.6 & 6.6 & $\begin{array}{l}\text { (1) DPP-4 }(0.703) \\
\text { (2) GLP-1 }(0.543) \\
\text { (3) Insulins }(0.481) \\
\text { (4) Sulfonylureas }(0.417)\end{array}$ \\
\hline 8 & 81 & Female & $\begin{array}{l}4,3,4,4 \\
\quad 4,4,2\end{array}$ & $\begin{array}{l}\text { MI, increasing_LDL-C, } \\
\text { Contraindications_CKD }\end{array}$ & DPP-4 & 8.6 & 9.0 & $\begin{array}{l}\text { (1) GLP-1 }(0.631) \\
\text { (2) Insulins }(0.445) \\
\text { (3) Sulfonylureas }(0.369)\end{array}$ \\
\hline 9 & 48 & Female & $\begin{array}{c}1,1,2,3 \\
\text { NaN, NaN, } 1\end{array}$ & $\begin{array}{l}\text { Patient_reluctance_about_injection, } \\
\text { increasing_LDL-C }\end{array}$ & $\mathrm{NaN}$ & 7.9 & 6.6 & $\begin{array}{l}\text { (1) Biguanides }(0.796) \\
\text { (2) GLP-1 }(0.560) \\
\text { (3) DPP-4 (0.558) } \\
\text { (4) Sulfonylureas }(0.248)\end{array}$ \\
\hline 10 & 56 & Male & $\begin{array}{l}\mathrm{NaN}, 2,2,2 \\
1,1, \mathrm{NaN}\end{array}$ & $\begin{array}{l}\text { Weight_gain, increasing_LDL-C, } \\
\text { Gastrointestinal_side_effects_nausea }\end{array}$ & TZDs & 7.9 & 7.8 & $\begin{array}{l}\text { (1) Biguanides (0.687) } \\
\text { (2) DPP-4 (0.313) }\end{array}$ \\
\hline
\end{tabular}

(see Table 11). All the scores are expressed as percentage. The evaluation results are shown in Table 12 . The clinical decision support system (CDSS) perceived 73\% satisfactions.
The results of antidiabetic medication recommendation indicate that the system has $70 \%$ satisfaction and $71 \%$ has intentions to use it. 
Table 11: Survey of "Patient-Centered Treatment Decision Support System for Diabetes Based on Fuzzy Logic and Domain Ontology".

\begin{tabular}{|c|c|c|c|c|c|}
\hline \multirow{2}{*}{ Question } & \multicolumn{5}{|c|}{ Scoring } \\
\hline & 1 & 2 & 3 & 4 & 5 \\
\hline \multicolumn{6}{|l|}{$\begin{array}{l}\text { What do you think about "Patient ideal } H b A 1 c \text { target inference"? } \\
\text { Are you satisfied with its accuracy? }\end{array}$} \\
\hline Is the "Method 1: Safety fuzzy rules" accurate? & $\square$ & $\square$ & $\square$ & $\square$ & $\square$ \\
\hline Are you satisfied with the results of the "Method 1: Safety fuzzy rules"? & $\square$ & $\square$ & $\square$ & $\square$ & $\square$ \\
\hline Is the "Method 2: Positivity fuzzy rules" accurate? & $\square$ & $\square$ & $\square$ & $\square$ & $\square$ \\
\hline Are you satisfied with the results of the "Method 2: Positivity fuzzy rules"? & $\square$ & $\square$ & $\square$ & $\square$ & $\square$ \\
\hline \multicolumn{6}{|l|}{$\begin{array}{l}\text { What do you think about "Antidiabetic medications reasoning and ranking"? } \\
\text { Are you satisfied with its accuracy? }\end{array}$} \\
\hline Is the "Antidiabetic medications reasoning and ranking" accurate? & $\square$ & $\square$ & $\square$ & $\square$ & $\square$ \\
\hline Are you satisfied with the results of the "Antidiabetic medications reasoning and ranking"? & $\square$ & $\square$ & $\square$ & $\square$ & $\square$ \\
\hline \multicolumn{6}{|l|}{ Do you think the system can provide some benefits for you? } \\
\hline Using the system improves my performance in my job. & $\square$ & $\square$ & $\square$ & $\square$ & $\square$ \\
\hline Using the system enhances my effectiveness in my job. & $\square$ & $\square$ & $\square$ & $\square$ & $\square$ \\
\hline I find the system to be useful in my job. & $\square$ & $\square$ & $\square$ & $\square$ & $\square$ \\
\hline \multicolumn{6}{|c|}{ If this system used in conjunction with the actual work, would you continue to use this system at work? } \\
\hline I enjoy using this system at work. & $\square$ & $\square$ & $\square$ & $\square$ & $\square$ \\
\hline I will frequently use this system in the future. & $\square$ & $\square$ & $\square$ & $\square$ & $\square$ \\
\hline I will strongly recommend to others to use this system. & $\square$ & $\square$ & $\square$ & $\square$ & $\square$ \\
\hline
\end{tabular}

Title: OEndocrinologists OAttending physicians OResident physicians

Gender: OMale OFemale

E-mail:

TABLE 12: The evaluation result of the system.

\begin{tabular}{lcc}
\hline Scores & \multicolumn{2}{c}{ Participants } \\
& $\begin{array}{c}\text { Endocrinologist } \\
\text { Attending physician } \\
\text { Resident physician }\end{array}$ & $\begin{array}{c}\text { Endocrinologist } \\
\text { Attending physician }\end{array}$ \\
\hline "HbA1c target inference (Safety fuzzy rules: Method 1)" Satisfaction degree (\%) & $67 \%$ & $80 \%$ \\
"HbA1c target inference (Positivity fuzzy rules: Method 2)" Satisfaction degree (\%) & $67 \%$ & $60 \%$ \\
"Antidiabetic medications reasoning and ranking" Satisfaction degree (\%) & $70 \%$ & $85 \%$ \\
Perceived usefulness (\%) & $73 \%$ & $87 \%$ \\
Intentions to use (\%) & $71 \%$ & $77 \%$ \\
\hline
\end{tabular}

According to the feedback of resident physicians, because the inpatients may have too many complications, so the resident physicians mostly use insulin to control $\mathrm{HbAlc}$. Therefore, the evaluation results of the resident physician will be relatively weak; this is because the recommendation system is only suitable for outpatients. So, if we exclude the results of the assessment of the resident physicians, the evaluation results of the system will be better. In this situation, the participating clinicians have $87 \%$ acceptance, and the likelihood of using the system at work and recommending it to others is $77 \%$.

The fuzzy safety rules (Method 1) has $80 \%$ accuracy and satisfaction, but the fuzzy positivity rules (Method 2) is only $60 \%$. So, the fuzzy safety rules (Method 1 ) is better than the fuzzy positivity rules (Method 2) for the patient ideal HbA1c target inference. The evaluation result of "Antidiabetic medications reasoning and ranking" shows that the system has
$85 \%$ satisfaction which can assist clinicians to the management of T2DM while selecting antidiabetic medications.

The user interface for the antidiabetic medication recommendation system is shown in Figure 7 . The website of the system is http://120.109.46.42/T2DM/. Doctors may refer to the system to make prescriptions. Of course, the system, which is likely to make misleading or inappropriate suggestions, cannot replace a doctor's clinical experience and professional judgment. The doctor thus makes the final decision.

\section{Discussion}

The number of patients with diabetes worldwide is significant and continually increasing. Diabetes imposes psychological, physical, and financial hardship on patients. Diabetes therapy, no doubt, is a complicated task. As regards the prescription strategy of clinical doctors, it is necessary that they consider 


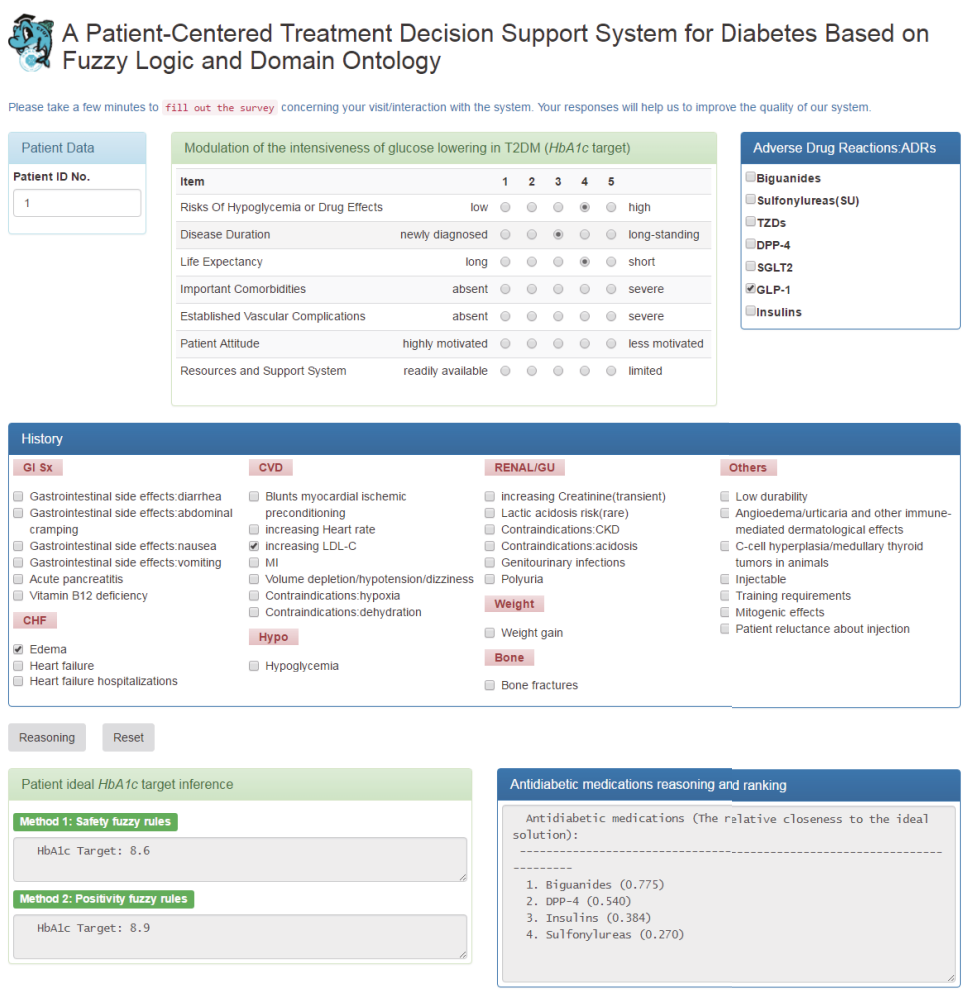

FiguRE 7: User interface for the antidiabetic medication recommendation system.

many factors. However, the following two reasons will affect the doctor's decision to use the system:

(1) If a doctor uses the new and expensive drugs as a treatment prescription, he will worry that the health insurance will not pay medical expenses. Then, he will only use the generic antidiabetic drugs.

(2) The system only provides a single drug treatment prescription, for long-term diabetes patients may need a multidrug treatment prescription to reduce HbA1c effectively.

Even so, CDSS is used to assist humans in making decisions rather than replacing human decisions. The system shows the following clinical values:

(a) Define appropriate therapeutic goals implementing patient-centered medical care and prescriptions:

The patient-centered management strategy, by contrast, holds that not all patients can benefit from active glucose management. It stresses individualized therapeutic goals. However, diabetes, multiple complications, and the complexity inherent in antidiabetic medication use often make it difficult for doctors, especially young doctors, to select the best therapeutic strategy. Despite their awareness of the concept of "patient-centered management strategy," it has shown the difficulty in practice. Given this, we systematized the constructs to help doctors develop their therapeutic goals and selection of prescriptions to meet the patient's needs. In addition to encouraging patients to follow doctors' instructions, this method can also reduce the risks resulting from medical treatment. Therapeutic goals may thus be achieved.

(b) Doctors can save time and make the best use of medical resources:

The increasing number of patients with type 2 diabetes has been exhausting medical resources. This system can enable doctors to spend less time on medical diagnosis and adjustment of patients' prescriptions. This will reduce the impact on health care resources.

(c) Doctors can employ the system with ease, and their clinical inertia can be reduced:

This system is manipulation-friendly. By inputting a few needed parameters, doctors can obtain recommended antidiabetic medications in order of effectiveness and thus make their treatment judgment accordingly. The system enables physicians to save time in answering patients' questions and can reduce the risk of developing clinical inertia.

\section{Conclusion and Future Work}

The prescription strategy of clinical doctors must take many factors into account. To address this, we developed an 
individualized antidiabetic medication recommendation system for patients with diabetes. This system, which can be manipulated with relative ease, tailors $H b A 1 c$ levels to mitigate patients' differences. Currently, 12 kinds of antidiabetic medications, both oral and injected, are available. Manually considering all possible conditions is not only a waste of medical resources but also a burden on the system, not to mention that it is impractical. This study, which combines fuzzy logic and ontology reasoning, proposes an antidiabetic medication recommendation system for patients with diabetes. It promotes a new concept of "patient-centered diabetes therapy." Antidiabetic medications are recommended for the outpatients, and useful ranking of medications is conducted. In addition to aiding doctors' clinical diagnosis, the system can not only serve as a guide for doctors specializing in diabetes but also help family practitioners and interns in prescribing medications.

Based on results of the study using the feedback system of operations, the seven factors analyzed can provide dynamic correlations. We will improve our system interface and dynamic weighting calculations in future research. Besides, we propose an architecture based on rules to build an antidiabetic medication recommendation system. In the future, we will combine rule-based and case-based reasoning to solve the special case issues.

\section{Conflicts of Interest}

The authors declare that there is no conflict of interest regarding the publication of this paper.

\section{Acknowledgments}

This work was supported by the Ministry of Science and Technology, Taiwan (Grant nos. 103-2632-E-324-001-MY3, MOST-104-2221-E-324-019-MY2, MOST-106-2221-E-324025, and MOST-106-2218-E-324-002).

\section{References}

[1] Institute of Medicine, Crossing the Quality Chasm: A New Health System for the 21st Century, The National Academies Press, Washington, DC, USA, 2001.

[2] C.-T. Bau, R.-C. Chen, and C.-Y. Huang, "Construction of a clinical decision support system for undergoing surgery based on domain ontology and rules reasoning," Telemedicine and e-Health, vol. 20, no. 5, pp. 460-472, 2014.

[3] F. J. Ampudia-Blasco, P. Y. Benhamou, G. Charpentier et al., "A decision support tool for appropriate glucose-lowering therapy in patients with type 2 diabetes," Diabetes Technology \& Therapeutics, vol. 17, no. 3, pp. 194-202, 2014.

[4] C.-L. Hwang, Y.-J. Lai, and T.-Y. Liu, "A new approach for multiple objective decision making," Computers \& Operations Research, vol. 20, no. 8, pp. 889-899, 1993.

[5] R. F. Alharbi, J. Berri, and S. El-Masri, "Ontology based clinical decision support system for diabetes diagnostic," in 2015 Science and Information Conference (SAI), pp. 597-602, London, UK, 2015.

[6] Stanford Center for Biomedical Informatics Research (BMIR), "Protégé," June 2017, http://protege.stanford.edu.
[7] R.-C. Chen, Y.-H. Huang, C.-T. Bau, and S.-M. Chen, "A recommendation system based on domain ontology and SWRL for anti-diabetic drugs selection," Expert Systems with Applications, vol. 39, no. 4, pp. 3995-4006, 2012.

[8] P. Sharma and P. D. Kaur, "Effectiveness of web-based social sensing in health information dissemination-a review," Telematics and Informatics, vol. 34, no. 1, pp. 194-219, 2017.

[9] Y.-F. Zhang, Y. Tian, T.-S. Zhou, K. Araki, and J.-S. Li, "Integrating HL7 RIM and ontology for unified knowledge and data representation in clinical decision support systems," Computer Methods and Programs in Biomedicine, vol. 123, pp. 94-108, 2016.

[10] D. E. Forbes, P. Wongthongtham, J. Singh, and S. C. Thompson, "Ontology supported assistive communications in healthcare," Communications of the Association for Information Systems, vol. 34, pp. 297-322, 2014.

[11] P. C. Sherimon and R. Krishnan, "OntoDiabetic: an ontologybased clinical decision support system for diabetic patients," Arabian Journal for Science and Engineering, vol. 41, no. 3, pp. 1145-1160, 2016.

[12] L. Marco-Ruiz, C. Pedrinaci, J. A. Maldonado, L. Panziera, R. Chen, and J. G. Bellika, "Publication, discovery and interoperability of clinical decision support systems: a linked data approach," Journal of Biomedical Informatics, vol. 62, pp. 243-264, 2016.

[13] S. E. Inzucchi, R. M. Bergenstal, J. B. Buse et al., "Management of hyperglycemia in type 2 diabetes: a patient-centered approach: position statement of the American Diabetes Association (ADA) and the European Association for the Study of diabetes (EASD)," Diabetes Care, vol. 35, no. 6, pp. 1364-1379, 2012.

[14] S. E. Inzucchi, R. M. Bergenstal, J. B. Buse et al., "Management of hyperglycemia in type 2 diabetes, 2015: a patient-centered approach: update to a position statement of the American Diabetes Association and the European Association for the Study of Diabetes," Diabetes Care, vol. 38, no. 1, pp. 140149, 2015.

[15] C.-H. Chang, Y.-D. Jiang, C.-H. Chung, L.-T. Ho, and L.-M. Chuang, "National trends in anti-diabetic treatment in Taiwan, 2000-2009," Journal of the Formosan Medical Association, vol. 111, no. 11, pp. 617-624, 2012.

[16] H.-T. Ou, K.-C. Chang, Y.-M. Liu, and J.-S. Wu, "Recent trends in the use of antidiabetic medications from 2008 to 2013: a nation-wide population-based study from Taiwan," Journal of Diabetes, vol. 9, no. 3, pp. 256-266, 2016.

[17] T. Kohro, T. Yamazaki, H. Sato et al., "Trends in antidiabetic prescription patterns in Japan from 2005 to 2011," International Heart Journal, vol. 54, no. 2, pp. 93-97, 2013.

[18] C. Rafaniello, V. Arcoraci, C. Ferrajolo et al., "Trends in the prescription of antidiabetic medications from 2009 to 2012 in a general practice of Southern Italy: a population-based study," Diabetes Research and Clinical Practice, vol. 108, no. 1, pp. 157-163, 2015.

[19] S.-H. Ko, D.-J. Kim, J.-H. Park et al., "Trends of antidiabetic drug use in adult type 2 diabetes in Korea in 2002-2013: nationwide population-based cohort study," Medicine, vol. 95, no. 27, article e4018, 2016.

[20] A. S. Abdelmoneim, D. T. Eurich, J.-M. Gamble, and S. H. Simpson, "Use patterns of antidiabetic regimens by patients with type 2 diabetes," Canadian Journal of Diabetes, vol. 37, no. 6, pp. 394-400, 2013. 
[21] J. C. Hsu, D. Ross-Degnan, A. K. Wagner et al., "Utilization of oral antidiabetic medications in Taiwan following strategies to promote access to medicines for chronic diseases in community pharmacies," Journal of Pharmaceutical Policy and Practice, vol. 8, no. 1, p. 15, 2015.

[22] R.-C. Chen, C.-Y. Huang, C.-T. Bau, and L.-S. Chen, "A decision support system for diabetes medicine selection using patient centered treatment based on fuzzy logic and domain ontology," International Journal of Innovative Computing, Information and Control, vol. 13, no. 5, pp. 16811692, 2017.

[23] A. J. Garber, M. J. Abrahamson, J. I. Barzilay et al., "Consensus statement by the American Association of Clinical Endocrinologists and American College of endocrinology on the comprehensive type 2 diabetes management algorithm 2016 executive summary," Endocrine Practice, vol. 22, no. 1, pp. 84-113, 2016.

[24] Y. Handelsman, Z. T. Bloomgarden, G. Grunberger et al., "American Association of Clinical Endocrinologists and American College of Endocrinology - clinical practice guidelines for developing a diabetes mellitus comprehensive care plan - 2015," Endocrine Practice, vol. 21, Supplement 1, pp. 1-87, 2015.

[25] J. Rada-Vilela, "FuzzyLite: a fuzzy logic control library," June 2017, http://www.fuzzylite.com.

[26] Stanford Center for Biomedical Informatics Research (BMIR), "WebProtégé," June 2017, http://protege.stanford. edu/products.php\#web-protege.

[27] Apache Software Foundation, “Apache Jena," June 2017, http://jena.apache.org.

[28] H. Rodbard, P. Jellinger, J. Davidson et al., "Statement by an American Association of Clinical Endocrinologists/American College of Endocrinology Consensus Panel on type 2 diabetes mellitus: an algorithm for glycemic control," Endocrine Practice, vol. 15, no. 6, pp. 540-559, 2009.

[29] A. J. Garber, M. J. Abrahamson, J. I. Barzilay et al., "AACE/ ACE Comprehensive diabetes management algorithm 2015," Endocrine Practice, vol. 21, no. 4, pp. 438-447, 2015.

[30] Y. Handelsman, Z. T. Bloomgarden, G. Grunberger et al., "American Association of Clinical Endocrinologists and American College of Endocrinology - clinical practice guidelines for developing a diabetes mellitus comprehensive care plan - 2015 - executive summary," Endocrine Practice, vol. 21, no. 4, pp. 413-437, 2015.

[31] A. Garber, M. Abrahamson, J. Barzilay et al., "American Association of Clinical Endocrinologists' comprehensive diabetes management algorithm 2013 consensus statement," Endocrine Practice, vol. 19, Supplement 2, pp. 1-48, 2013.

[32] C.-L. Hwang and K. Yoon, Multiple Attribute Decision Making: Methods and Applications: A State-of-the-Art Survey. Lecture Notes in Economics and Mathematical Systems, vol. 186, Springer-Verlag, Berlin, Heidelberg, 1981.

[33] Wikipedia, “TOPSIS,” June 2017, https://en.wikipedia.org/ wiki/TOPSIS.

[34] S.-S. Chang, Fuzzy Multi-Criteria Decision Making for Evaluation Method, Wu-Nan Book Inc., Taiwan, 2012. 


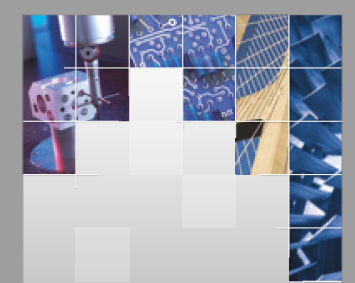

\section{Enfincering}
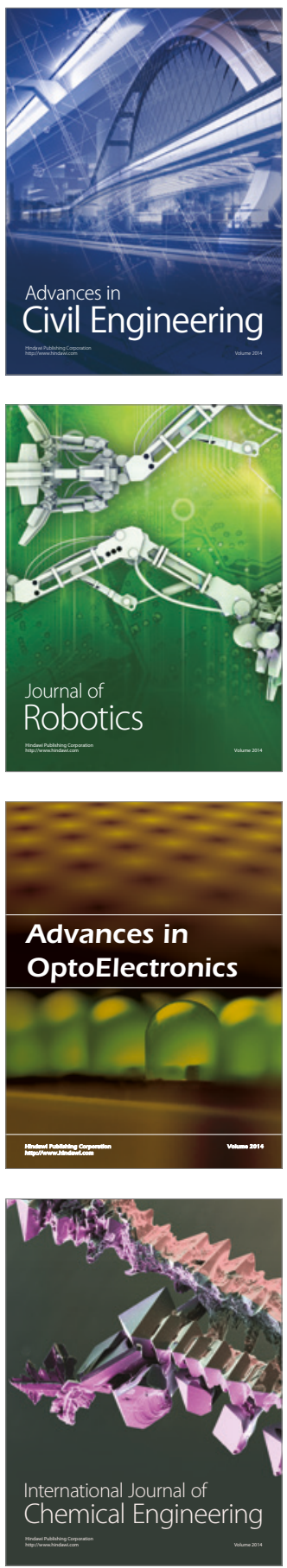

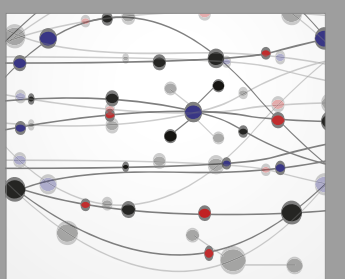

The Scientific World Journal

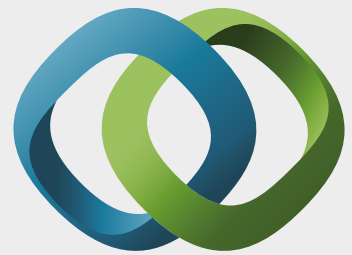

\section{Hindawi}

Submit your manuscripts at

https://www.hindawi.com
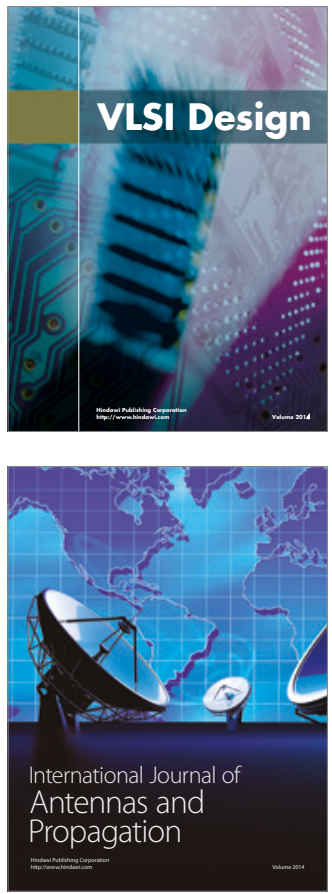

\section{Rotating}

Machinery
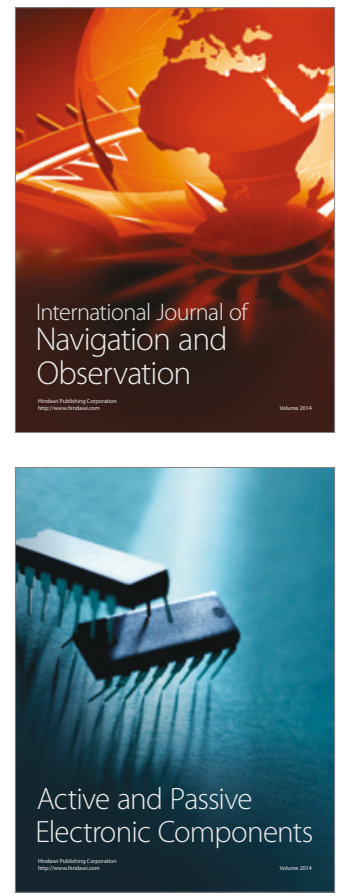
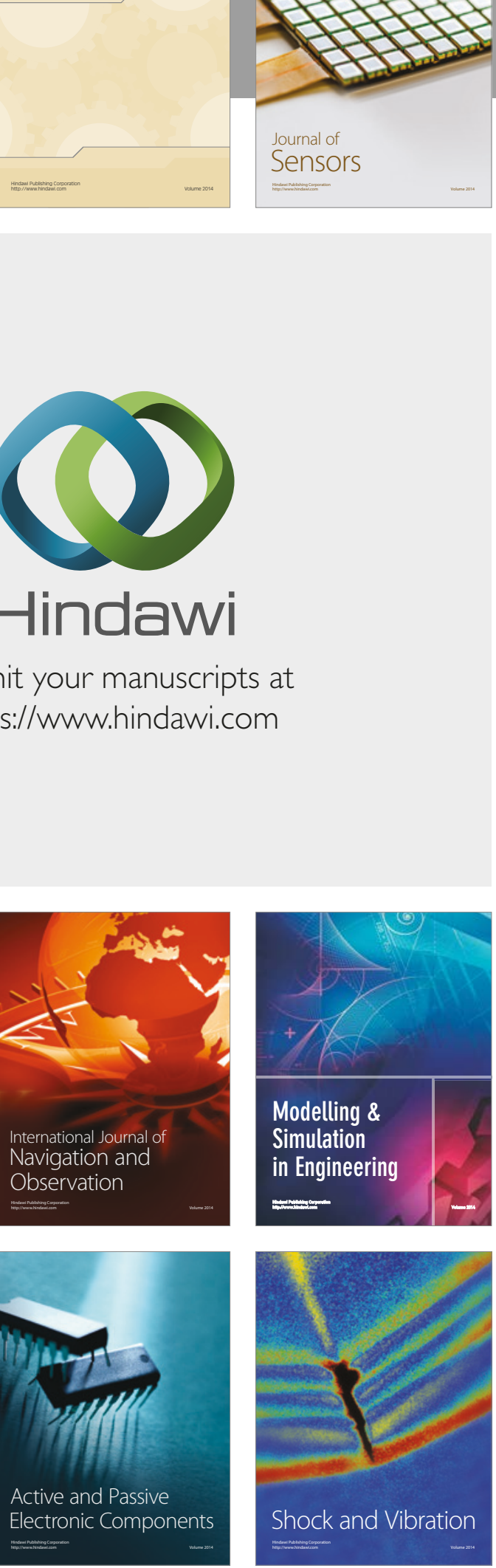
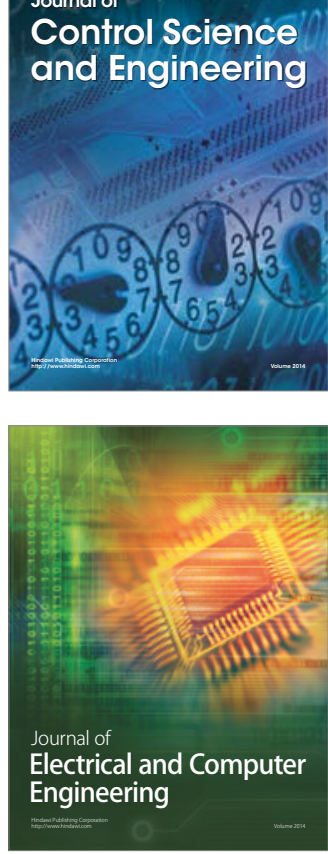

Distributed

Journal of

Control Science

and Engineering
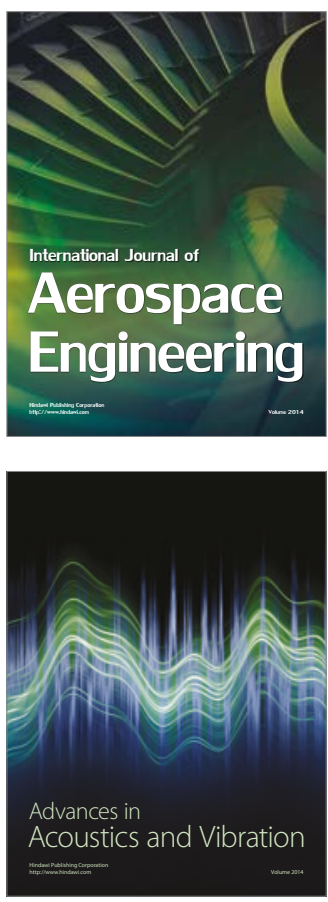

Sensor Networks 